\title{
Ethnic Variation in Consumption of Traditional Tobacco Products and Lung Cancer Risk in Nepal
}

\author{
Greg A Raspanti' ${ }^{1}$, Mia Hashibe ${ }^{2}$, Bhola Siwakoti ${ }^{3}$, Mei Wei ${ }^{2}$, Binay Kumar \\ Thakur ${ }^{3}$, Chin Bahadur Pun ${ }^{3}$, Charles Milrod ${ }^{1}$, Subodh Adhikari' ${ }^{1}$, Yuan-Chin \\ Amy Lee ${ }^{2}$, Amir Sapkota ${ }^{1 *}$
}

\begin{abstract}
Lung cancer is the leading contributor to cancer deaths in the developing world. Within countries, significant variability exists in the prevalence of lung cancer risk, yet limited information is available whether some of the observed variability is associated with differences in the consumption pattern of local tobacco products with differing potency. We recruited 606 lung cancer cases and 606 controls from the B.P. Koirala Memorial Cancer Hospital in Nepal from 2009-2012. We estimated odds ratios (ORs) and 95\% confidence intervals (CI) for lung cancer risk associated with different tobacco products, using unconditional logistic regression. Unfiltered cigarettes tended to be the most frequently used products across ethnic subgroup with about $53.7 \%$ of Brahmins, $60.1 \%$ of Chettris, and 52.3\% of Rai/Limbu/Magar/others. In contrast, about 39.9\% of Madishe/Tharu smokers reported using bidi compared with only $27.7 \%$ who smoked unfiltered cigarettes. Among those who only smoked one type of product, choor/kankat smokers had the highest lung cancer risk (OR 10.2; 95\% CI 6.2-16.6), followed by bidi smokers (OR 5.6; 95\% CI 3.6-8.7), unfiltered cigarettes (OR 4.9; 95\% CI 3.4-7.2), and filtered cigarettes (OR 3.4; 95\% CI 2.2-5.3). A clear dose-response relationship was observed between increased frequency of smoking and lung cancer risk across all ethnic subgroups. These results highlight the important role of traditional tobacco products on lung cancer risk in the low income countries.
\end{abstract}

Keywords: Local tobacco - lung cancer - Nepal - ethnic disparities

Asian Pac J Cancer Prev, 16 (14), 5721-5726

\section{Introduction}

Mortality from cancer is on the rise, particularly among low and middle income countries around the world (WHO, 2012). Of the estimated 8.2 million deaths globally attributed to cancer, approximately $70 \%$ occurred in low and middle income countries (IARC, 2012). In most of these areas, lung cancer is the leading contributor to cancer deaths accounting for an estimated 1.59 million deaths (IARC, 2012). Majority of these cases are related to tobacco smoking, which accounts for roughly $22 \%$ of global cancer deaths and $71 \%$ of lung cancer deaths (IOM, 2007; WHO, 2012). However, there is considerable variability in the type of tobacco products used, particularly in the low income countries. With a projected increase in lung cancer in the region, understanding the lung cancer risk associated with these local tobacco products is important to inform more meaningful and culturally competent intervention strategies (Bhagabaty et al., 2015; D'Souza et al., 2013; Thapa and Sayami, 2014).

Lung cancer is the most common cancer in both males and females in Nepal - one of the poorest countries in the world with 30 million people - accounting for $20 \%$ of all cancer cases (Binu et al., 2007; Pradhananga et al., 2009; World Bank, 2012). Nepalese men are known to smoke more frequently and for longer duration compared to women (Chawla et al., 2010; Noronha et al., 2012). Approximately, $52 \%$ of Nepalese men smoke some form of tobacco products, while $13 \%$ of women reported smoking tobacco (ICF International, 2012). The most common used tobacco product in Nepal is filtered cigarettes accounting for approximately $30 \%$ of male smokers (ICF International, 2012). But there is considerable variation in female smoking prevalence across race and ethnicity as well as geographic areas. This variability in female smoking prevalence is linked to how smoking is perceived across the subgroups. Among Brahmins, smoking by females is considered socially unacceptable in contrast to Rai/Limbu/Magar/Other where smoking by females is more acceptable. In addition to the differences in smoking prevalence across ethnic subgroups, there is considerable difference in the type of local tobacco products consumed by these subgroups. Limited work has been conducted in Nepal, while an increasing body of literature suggests

${ }^{1}$ Maryland Institute for Applied Environmental Health, University of Maryland College Park School of Public Health, Maryland, ${ }^{2}$ Division of Public Health, Department of Family and Preventive Medicine, Huntsman Cancer Institute, University of Utah School of Medicine, Salt Lake City, Utah, USA, ${ }^{3}$ B.P. Koirala Memorial Cancer Hospital, Bharatpur, Chitwan, Nepal *For correspondence: amirsap@umd.edu 
that the potency of these local tobacco products is not similar in neighboring India (Jayalekshmy et al., 2008; Prasad et al., 2009; Prasad et al., 2010; Pednekar et al., 2011; Noronha et al., 2012). For example, several studies in India have shown that bidi smoking is associated with higher risk of lung cancer risk compared to commercial cigarettes (Notani and Sanghvi, 1974; Notani et al., 1977; Jussawalla and Jain, 1979; Dikshit and Kanhere, 2000; D. Gupta et al., 2001; Prasad et al., 2010; Ganesh et al., 2011). Smokers in Nepal use additional loose tobacco that they hand roll into a cigarette, commonly locally referred to as choor/kankat and cancer potency of such products remain unknown.

In this paper, we used data from hospital-based case control study from Nepal to i) quantify lung cancer risk associated with local tobacco products that are commonly used in Nepal (bidi and choor/kankat) versus commercial tobacco smoking (filtered and unfiltered cigarettes) and ii) investigate if the observed racial/ethnic differences in lung cancer risk in Nepal is associated with the differences in type of local tobacco product used.

\section{Materials and Methods}

A hospital-based case-control study was conducted at the B.P. Koirala Memorial Cancer Hospital (BPKMCH), located in the city of Bharatpur, Chitwan District, Nepal, from November 2009 through December 2012. Located 150 kilometers southwest of Kathmandu, BPKMCH is the major cancer hospital in Nepal. The details regarding participant recruitment and biological sample collections have been described previously (Hashibe et al., 2011). In brief, 606 incident lung cancer cases and 606 controls were recruited from the hospital after receiving informed consent.

The inclusion criteria for a lung cancer case were: 1) 18 years of age or older 2) resident of Nepal for at least five years and 3) admitted to BPKMCH. The eligible cases were recruited as soon as possible following lung cancer diagnosis with a target interval of one day and a maximum interval of 4 weeks. A trained medical staff reviewed medical records to extract relevant diagnostic information, including the date and method of diagnosis, histological type, tumor location, stage, and grade. Final diagnosis of lung cancer was confirmed with histological, cytological, or X-ray based evidence. The control population was selected from various hospital visitors to frequency match the distribution of the case population by age (+/-) 5 years, sex, ethnicity, and residence. The controls were visitors at BPKMCH excluding family members of participating lung cancer cases. Prior to field implementation, standardized lifestyle and food frequency questionnaires were translated into Nepali language by native speakers and pilot tested in the field. Locally trained interviewers collected information on demographic characteristics, education, residential mobility throughout lifetime, type of cooking and heating fuel used at each residence, occupational history, and family history of cancer. The study was approved by the Institutional Review Board at the University of Utah, University of Maryland as well as the Government of Nepal (Nepal
Health Research Council).

Tobacco use data was derived from questionnaires completed immediately following participant enrollment. Participants were asked if they have smoked more than 100 cigarette/bidi/kankat/choor over their lifetime. Nonsmokers are classified as those who answered "no" to the aforementioned question and non-smokers are used as the reference group during analysis. If answered "yes", the participant then reported the age of starting and stopping (if appropriate) and quantity used per day for each type of tobacco product individually. We computed a lifetime profile of smoking habits based on duration and frequency of each type of tobacco products used. Furthermore, these profiles were categorized to reflect single vs. multiple product users. The type of tobacco products included: filtered cigarettes, unfiltered cigarettes, bidi, and choor/ kankat. The last category (choor/kankat) is loose local tobacco products that individuals wrap themselves. Dichotomous variables were created to reflect the use of each type of tobacco products. A variable reflecting duration and frequency of smoking was created for each product type [PACKYEARS = reported duration of smoking in years $x$ frequency of smoking / 20]. These product specific PY variables were summed to generate total pack years.

In addition, we also computed exposure to household air pollution derived from solid cooking fuels (HAP) based on residential history and type of fuel used for cooking at each residence. We calculated a composite index of SES using scores for level of education, household income, and crowdedness (number of individuals living per room) as previously described (Ghosh and Ghosh, 2009; Sapkota et al., 2008).

We used unconditional logistic regression to estimate the odds ratios (ORs) and 95\% confidence intervals (95\%CIs) for lung cancer risk associated with different traditional and commercial tobacco products and duration of tobacco use. The models were adjusted for sex (male/ female), ethnicity, zone of residence, age, HAP index, and SES index. These potential confounding variables were chosen based on prior literature documenting their influence on lung cancer risk and smoking habits. We considered adjusting for family history of lung cancer to account for the influence of genetic susceptibility. However, only two individuals in the study reported a family member with lung cancer and in both instances the family members were smokers.

\section{Results}

The demographic characteristics of the study participants are provided in Table 1 . In this study, males accounted for $56 \%$ of the total study population compared to $44 \%$ for females. In general, cases tended to be slightly older and less educated compared to controls. The vast majority of both cases (88\%) and controls (91\%) were Hindus. The largest ethnic groups for cases were Chettri, Brahmin, Magar, and Madishe (20.5\%, 19.3\%, 17.3\%, and $10.1 \%$ respectively). In comparison, the largest control groups were Brahmin, Chettri, Madishe, and Magar accounting for $25.2 \%, 17.2 \%, 12.9 \%$, and $7.4 \%$ of the 
Ethnic Variation in Consumption of Traditional Tobacco Products and Lung Cancer Risk in Nepal

control population respectively. The largest difference between cases and controls observed in this study was in the Magar caste, accounting for $17.3 \%$ of cases but only $7.4 \%$ of the controls. About $23.7 \%$ of cases and $29.7 \%$ of controls are classified as "other". Ethnic groups not included in the questionnaire include Janajati and Dalit groups as well as other smaller sub-populations not captured by the questionnaire options.

Overall, the average years of tobacco use was 40.3 years. Compared to controls, lung cancer cases smoked tobacco longer (mean in years: $55.2 \mathrm{vs}$. 25.5; p-value<0.001) and more frequently (PY: 30.4 vs. 17.6; p-value $<0.001)$. We observed variation in smoking prevalence and type of tobacco products used within ethnic subgroups (Table 2). Ethnic subgroups were combined based upon cultural and geographical similarities. Across all subgroups, unfiltered cigarettes was the most frequently used tobacco product, with prevalence ranging from $60.1 \%$ of Chettri to $52.3 \%$ of Rai/Limbu/Magar/Other. A noted exception to this was the Madishe/Tharu group for whom the predominant tobacco product was bidi (39.9\%) followed by unfiltered cigarettes $(27.7 \%)$.

Not surprisingly, ever smokers had an increased risk of lung cancer when compared to those who reported never smoking (OR 4.95; 95\%CI 3.50-7.01). We observed increased lung cancer risk among females compared with males (OR 1.76; 95\%CI 1.34-2.36) and older participants (OR 1.05; 95\%CI 1.03-1.06). Furthermore, we observed a decreasing lung cancer risk as SES increased (OR 0.76; 95\% CI 0.66-0.87). Overall, all types of tobacco product usage were independently associated with increased lung cancer risk compared with non smokers (Table 3). Specifically we observed highest product specific risk for choor/kankat (OR 11.2; 95\%CI 6.6-19.3) followed by bidi

Table 1. Demographic Characteristics of the Study Population

\begin{tabular}{|c|c|c|c|c|c|}
\hline \multirow[t]{2}{*}{ Demographic Charecterstics } & \multicolumn{2}{|c|}{ Lung Cancer Cases } & \multicolumn{2}{|c|}{ Controls } & \multirow[t]{2}{*}{$c^{2}(p-v a l u e)$} \\
\hline & $\overline{\mathrm{N}}$ & $\%$ & $\mathrm{~N}$ & $\%$ & \\
\hline Age & & & & & $98.5(<0.001)$ \\
\hline$<40$ & 27 & 4.5 & 24 & 3.9 & \\
\hline $40-49$ & 45 & 7.4 & 121 & 19.9 & \\
\hline $50-59$ & 152 & 25.1 & 231 & 38.1 & \\
\hline $60-69$ & 251 & 41.4 & 179 & 29.5 & \\
\hline $70+$ & 131 & 21.6 & 51 & 8.4 & \\
\hline Gender & & & & & $6.0(0.01)$ \\
\hline Male & 338 & 55.8 & 380 & 62.7 & \\
\hline Female & 268 & 44.2 & 226 & 37.3 & \\
\hline SES Index & & & & & $49.3(<0.001)$ \\
\hline Q1 (Low) & 180 & 29.7 & 109 & 18 & \\
\hline Q2 (Mid-Low) & 170 & 28.1 & 150 & 24.8 & \\
\hline Q3 (Mid-High) & 153 & 25.6 & 148 & 24.4 & \\
\hline Q4 (High) & 103 & 17 & 199 & 32.8 & \\
\hline Ethnicity & & & & & $47.5(<0.001)$ \\
\hline Brahmin & 117 & 19.3 & 153 & 25.3 & \\
\hline Chettri & 124 & 20.5 & 104 & 17.2 & \\
\hline Rai & 20 & 3.3 & 14 & 2.3 & \\
\hline Madishe & 61 & 10.1 & 78 & 12.9 & \\
\hline Limbu & 17 & 2.8 & 4 & 0.7 & \\
\hline Magar & 105 & 17.3 & 45 & 7.4 & \\
\hline Tharu & 21 & 3.5 & 28 & 4.6 & \\
\hline Other & 141 & 23.3 & 180 & 29.7 & \\
\hline Fuel Use & & & & & $3.2(0.52)$ \\
\hline Modern Fuel & 42 & 6.9 & 48 & 7.9 & \\
\hline Wood Only & 555 & 91.6 & 541 & 89.3 & \\
\hline Coal Only & 4 & 0.7 & 6 & 1 & \\
\hline Biomass Only & 4 & 0.7 & 9 & 1.5 & \\
\hline Kerosene Only & 1 & 0.2 & 2 & 0.3 & \\
\hline Zone of Residence & & & & & $56.6(<0.001)$ \\
\hline Bagmati & 9 & 1.5 & 9 & 1.5 & \\
\hline Bheri & 36 & 6.1 & 24 & 4 & \\
\hline Dhaulagiri & 25 & 4.2 & 17 & 2.9 & \\
\hline Gandaki & 91 & 15.3 & 55 & 9.2 & \\
\hline Janakpur & 33 & 5.6 & 40 & 6.7 & \\
\hline Karnali & 11 & 1.9 & 4 & 0.7 & \\
\hline Koshi & 59 & 9.9 & 50 & 8.4 & \\
\hline Lumbini & 116 & 19.5 & 114 & 19.1 & \\
\hline Mahakali & 13 & 2.2 & 14 & 2.4 & \\
\hline Mechi & 24 & 4 & 24 & 4 & \\
\hline Narayani & 72 & 12.1 & 162 & 27.2 & \\
\hline Rapti & 45 & 7.6 & 38 & 6.4 & \\
\hline Sagarmatha & 41 & 6.9 & 36 & 6 & \\
\hline
\end{tabular}


(OR 6.1; 95\%CI 4.2-9.1), unfiltered cigarettes (OR 5.6; 95\% CI 3.9-8.1), and filtered cigarettes (OR 4.2; 95\%CI 2.8-6.2) when compared to non smokers. Across ethnic subgroups, all tobacco products were associated with an increased lung cancer risk compared with non-smokers; however, the degree of the association varied by ethnic subgroup. Among Brahmins the highest product specific OR was observed for choor/kankat, followed by bidi and unfiltered cigarettes [OR (95\%CI) 11.7 (5.0-27.4), 10.9 (5.1-23.1), 9.2 (4.5-18.7) respectively]. Chettri, Madishe/ Tharu, and Rai/Limbu/Magar/Other groups showed similar patterns with the highest product specific ORs observed for choor/kankat [OR (95\%CI) 9.1 (3.5-23.4), 14.1 (5.6-35.9), and 6.9 (3.6-13.1) respectively], followed by bidi [OR (95\%CI) 6.9 (3.1-15.8), 7.2 (3.4-35.9), and $5.2(3.0-8.8)$ respectively] and unfiltered cigarettes [OR (95\%CI) 5.6 (2.5-12.5), 6.1 (2.9-12.8), and 4.5 (2.7-7.4) respectively].

We conducted sub analysis where multiple product users were assigned to a single product that was used for the longest duration. This did not change our overall findings significantly. Similarly to the previous analysis, the highest product specific ORs were observed for choor/ kankat (OR 10.2; 95\%CI 6.2-16.6) followed by bidi (OR

Table 2. Prevalence of Specific Tobacco Product Consumptions by Ethnicity and Lung Cancer Status

\begin{tabular}{|c|c|c|c|c|c|c|}
\hline \multirow[t]{2}{*}{ Ethnicity } & \multicolumn{2}{|c|}{ Non-Smokers } & \multicolumn{2}{|c|}{ Choor/Kankat } & \multicolumn{2}{|c|}{ Bidi } \\
\hline & Case & Control & Case & Control & Case & Control \\
\hline Brahmin & $12(3.7 \%)$ & $65(24.1 \%)$ & $28(10.4 \%)$ & $13(4.8 \%)$ & $34(12.6 \%)$ & $21(7.8 \%)$ \\
\hline Chettri & $9(3.5 \%)$ & $35(15.4 \%)$ & $38(16.7 \%)$ & $15(6.6 \%)$ & $46(20.2 \%)$ & $18(7.9 \%)$ \\
\hline Madishe/Tharu & $10(5.4 \%)$ & $52(27.6 \%)$ & $11(5.8 \%)$ & $6(3.2 \%)$ & $49(26.1 \%)$ & $26(13.8 \%)$ \\
\hline Rai/Limbu/Magar & $28(5.1 \%)$ & $92(17.1 \%)$ & $62(11.8 \%)$ & $25(4.8 \%)$ & $95(18.0 \%)$ & $57(10.8 \%)$ \\
\hline \multirow[t]{2}{*}{ Ethnicity } & \multicolumn{2}{|c|}{ Filtered Cigarettes } & \multicolumn{2}{|c|}{ Unfiltered Cigarettes } & & \\
\hline & Case & Control & Case & Control & & \\
\hline Brahmin & $36(13.3 \%)$ & $40(14.8 \%)$ & $83(30.7 \%)$ & $63(23.3 \%)$ & & \\
\hline Chettri & $39(17.1 \%)$ & $29(12.7 \%)$ & $86(37.7 \%)$ & $51(22.3 \%)$ & & \\
\hline Madishe/Tharu & $19(10.1 \%)$ & $27(14.4 \%)$ & $28(14.9 \%)$ & $25(13.3 \%)$ & & \\
\hline Rai/Limbu/Magar & $67(12.7 \%)$ & $52(9.9 \%)$ & $189(35.9 \%)$ & $89(16.9 \%)$ & & \\
\hline
\end{tabular}

Table 3. Product Specific Odds Ratios and $95 \%$ Confidence Interval by Ethnicity

\begin{tabular}{|c|c|c|c|c|c|c|c|c|c|}
\hline \multirow[t]{2}{*}{ Tobacco Products } & \multicolumn{3}{|c|}{ Overall } & \multicolumn{3}{|c|}{ Brahmin } & \multicolumn{3}{|c|}{ Chettri } \\
\hline & $\mathrm{CS} / \mathrm{CNT}$ & $\mathrm{OR}^{*}$ & $95 \% \mathrm{CI}$ & $\mathrm{CS} / \mathrm{CNT}$ & $\mathrm{OR}^{*}$ & $95 \% \mathrm{CI}$ & $\mathrm{CS} / \mathrm{CNT}$ & $\mathrm{OR}^{*}$ & $95 \% \mathrm{CI}$ \\
\hline Non smokers & $59 / 244$ & 1.0 & & $12 / 65$ & 1.0 & & $9 / 35$ & 1.0 & \\
\hline Choor/Kankat & $113 / 39$ & 10.2 & $6.2-16.6$ & $17 / 9$ & 13.5 & $5.8-31.2$ & 29/11 & 9.8 & $2.9-25.5$ \\
\hline Bidi & $111 / 74$ & 5.6 & $3.6-8.7$ & $11 / 14$ & 8.7 & $3.9-19.8$ & $18 / 11$ & 5.9 & 2.4- 14.2 \\
\hline Filtered Cigarettes & $74 / 89$ & 3.4 & $2.2-5.3$ & $20 / 26$ & 3.7 & $1.7-8.1$ & $17 / 11$ & 2.5 & $1.1-5.7$ \\
\hline Unfiltered Cigarettes & $245 / 157$ & 4.9 & $3.4-7.2$ & $55 / 39$ & 6.7 & $3.2-14.1$ & $51 / 35$ & 4.3 & $1.9-9.9$ \\
\hline \multirow[t]{2}{*}{ Tobacco Products } & \multicolumn{3}{|c|}{ Madishe/Tharu } & \multicolumn{3}{|c|}{ Rai/Limbu/Magar/Other } & & & \\
\hline & $\mathrm{CS} / \mathrm{CNT}$ & $\mathrm{OR} *$ & $95 \% \mathrm{CI}$ & $\mathrm{CS} / \mathrm{CNT}$ & $\mathrm{OR}^{*}$ & $95 \% \mathrm{CI}$ & & & \\
\hline Non smokers & $10 / 52$ & 1.0 & $28 / 92$ & 1.0 & & & & & \\
\hline Choor/Kankat & $12 / 4$ & 16.4 & $6.5-41.4$ & $55 / 15$ & 8.1 & $4.3-15.4$ & & & \\
\hline Bidi & $39 / 19$ & 8.6 & $3.7-20.1$ & $43 / 30$ & 4.6 & $2.6-8.3$ & & & \\
\hline Filtered Cigarettes & $9 / 15$ & 3.8 & $1.7-8.6$ & $28 / 37$ & 2.2 & $1.2-3.9$ & & & \\
\hline Unfiltered Cigarettes & $11 / 15$ & 5.4 & $2.5-11.7$ & $128 / 67$ & 3.8 & $2.2-6.4$ & & & \\
\hline
\end{tabular}

*adjusted for age, sex, SES, HAP exposure, zone of residence

Table 4. Number of Tobacco Products Used and Lung Cancer Risk by Ethnicity

\begin{tabular}{|c|c|c|c|c|c|c|c|c|c|}
\hline \multirow[t]{2}{*}{ \# of Products Used } & \multicolumn{3}{|c|}{ Overall } & \multicolumn{3}{|c|}{ Brahmin } & \multicolumn{3}{|c|}{ Chettri } \\
\hline & $\mathrm{CS} / \mathrm{CNt}$ & $\mathrm{OR}^{*}$ & $95 \% \mathrm{CI}$ & $\mathrm{CS} / \mathrm{CNt}$ & $\mathrm{OR}^{*}$ & $95 \% \mathrm{CI}$ & $\mathrm{CS} / \mathrm{CNt}$ & $\mathrm{OR} *$ & $95 \% \mathrm{CI}$ \\
\hline 0 & $59 / 244$ & 1.0 & & $12 / 65$ & 1.0 & & $9 / 35$ & 1.0 & \\
\hline 1 & $302 / 231$ & 4.2 & $2.9-6.1$ & $55 / 54$ & 6.0 & $2.9-12.6$ & $63 / 38$ & 3.9 & $1.7-9$ \\
\hline 2 & $150 / 84$ & 6.3 & $4.1-9.6$ & $36 / 21$ & 9.9 & $4.5-22.1$ & $20 / 19$ & 6.9 & $2.9-16.6$ \\
\hline $3+$ & $96 / 47$ & 7.0 & $4.3-11.4$ & $16 / 12$ & 13.5 & $5.5-33.6$ & $33 / 11$ & 10.5 & $3.8-28.5$ \\
\hline \multirow[t]{2}{*}{ \# of Products Used } & \multicolumn{3}{|c|}{ Madishe/Tharu } & \multicolumn{3}{|c|}{ Rai/Limbu/Magar/Other } & & & \\
\hline & $\mathrm{CS} / \mathrm{CNt}$ & $\mathrm{OR} *$ & $95 \% \mathrm{CI}$ & $\mathrm{CS} / \mathrm{CNt}$ & $\mathrm{OR} *$ & $95 \% \mathrm{CI}$ & & & \\
\hline 0 & $10 / 52$ & 1.0 & & $28 / 92$ & 1.0 & & & & \\
\hline 1 & $39 / 36$ & 4.8 & $2.0-11.5$ & $145 / 103$ & 3.4 & $2.0-5.8$ & & & \\
\hline 2 & $22 / 12$ & 9.2 & $3.2-26.3$ & $72 / 32$ & 5.5 & $2.9-10.5$ & & & \\
\hline $3+$ & $8 / 15$ & 5.9 & $1.6-21.9$ & $39 / 17$ & 5.1 & $2.3-11.0$ & & & \\
\hline
\end{tabular}

*adjusted for age, sex, SES, HAP exposure, zone of residence 
Ethnic Variation in Consumption of Traditional Tobacco Products and Lung Cancer Risk in Nepal

Table 5. Tobacco Pack Years and Lung Cancer Risk by Ethnicity

\begin{tabular}{|c|c|c|c|c|c|c|c|c|c|}
\hline \multirow{2}{*}{$\begin{array}{c}\text { Tobacco } \\
\text { Pack } \\
\text { Years }\end{array}$} & \multicolumn{3}{|c|}{ Overall } & \multicolumn{3}{|c|}{ Brahmin } & \multicolumn{3}{|c|}{ Chettri } \\
\hline & $\mathrm{CS} / \mathrm{CNT}$ & $\mathrm{OR}^{*}$ & $95 \% \mathrm{CI}$ & $\mathrm{CS} / \mathrm{CNT}$ & $\mathrm{OR}^{*}$ & $95 \% \mathrm{CI}$ & $\mathrm{CS} / \mathrm{CNT}$ & $\mathrm{OR} *$ & $95 \% \mathrm{CI}$ \\
\hline 0 & $59 / 244$ & 1.0 & & $12 / 65$ & 1.0 & & $9 / 35$ & 1.0 & \\
\hline $1-15.0$ & $175 / 210$ & 3.2 & $2.2-4.6$ & $27 / 45$ & 5.1 & $2.4-10.8$ & $39 / 33$ & 3.4 & $1.4-7.8$ \\
\hline $15.01-30$ & $150 / 79$ & 8.8 & $5.5-14.4$ & $23 / 18$ & 10.5 & $4.5-24.1$ & $29 / 19$ & 7.5 & $3.0-19.2$ \\
\hline \multirow[t]{2}{*}{$30+$} & $223 / 73$ & 16.2 & $9.7-27.2$ & $57 / 24$ & 23.7 & $9.5-59.2$ & $48 / 16$ & 17.4 & $6.4-47.3$ \\
\hline & \multicolumn{3}{|c|}{ Ptrend $<0.001$} & \multicolumn{3}{|c|}{ Ptrend $<0.001$} & \multicolumn{3}{|c|}{ Ptrend $<0.001$} \\
\hline \multirow{2}{*}{$\begin{array}{c}\text { Tobacco } \\
\text { Pack } \\
\text { Years }\end{array}$} & \multicolumn{3}{|c|}{ Madishe/Tharu } & \multicolumn{6}{|c|}{ Rai/Limbu/Magar/Other } \\
\hline & $\mathrm{CS} / \mathrm{CNT}$ & $\mathrm{OR}^{*}$ & $95 \% \mathrm{CI}$ & \multicolumn{2}{|c|}{$\mathrm{CS} / \mathrm{CNT}$} & \multicolumn{2}{|c|}{$\mathrm{OR}^{*}$} & \multicolumn{2}{|c|}{$95 \% \mathrm{CI}$} \\
\hline 0 & $10 / 52$ & 1.0 & & \multicolumn{2}{|c|}{$28 / 92$} & \multicolumn{2}{|c|}{1.0} & & \\
\hline $1-15.0$ & $27 / 37$ & 3.4 & $1.4-8.4$ & \multicolumn{2}{|c|}{$82 / 95$} & \multicolumn{2}{|c|}{2.5} & \multicolumn{2}{|c|}{$1.4-4.3$} \\
\hline $15.01-30$ & $17 / 11$ & 8.9 & 2.9-26.9 & & & & & \multicolumn{2}{|c|}{$3.2-11.9$} \\
\hline \multirow[t]{2}{*}{$30+$} & $25 / 7$ & 19.9 & $6.0-66.0$ & & & & & & 17.9 \\
\hline & \multicolumn{3}{|c|}{ Ptrend $<0.001$} & \multicolumn{6}{|c|}{ Ptrend $<0.001$} \\
\hline
\end{tabular}

*adjusted for age, sex, SES, HAP exposure, zone of residence

5.6; 95\% CI 3.6-8.7) and unfiltered cigarettes (OR 4.9; 95\% CI 3.4-7.2). We observed the similar product specific effects when stratified across all ethnic subgroups.

We detected associations between the number of tobacco products used and lung cancer risk (Table 4). Lung cancer risk appeared to increase linearly with number of tobacco products consumed, with a noted exception for Madishe/Tharu groups (Table 4). Overall, the highest observed OR was for those who reported using 3 or more types of tobacco products (OR 7.0; 95\%CI 4.3-11.4) compared with non smokers. Similar trends were observed for every ethnic group with highest lung cancer risk among those reporting using 3 or more types of tobacco.

To investigate if the frequency and duration of smoking has a different effect across the ethnic subgroups, we stratified the analysis for tobacco PY and lung cancer risk by ethnicity (Table 5). Within each group, we detected exposure-response relationships between the tobacco PY and the risk of lung cancer (Ptrend $<0.001)$. We observed potential variability in the strength of association across ethnic subgroups. For example, the effect estimate for the highest exposure group (30+ PY) varied from 9.1 (CI 4.7-17.9) for Rai/Limbu/Other group to 23.7 (CI 9.5-59.2) for Brahmin group.

\section{Discussion}

We analyzed data from a hospital based case-control study of lung cancer in Nepal to investigate possible differences in lung cancer risk across different ethnic subgroups with differences in smoking prevalence as well as the specific types of tobacco products consumed.

We observed significant differences among the type of tobacco used by ethnic subgroups. Large percentages of Brahmin, Chettri, and Rai/Limbu/Magar/Other smokers used unfiltered cigarettes compared to Madishe/Tharu smokers who tended to use bidi. Analysis focused on product specific effects showed those using choor/kankat had the highest risk followed by bidi and unfiltered cigarettes. The differences observed between those smoking multiple types of tobacco products may be driven by underlying social and cultural perceptions held by the specific group.

A clear exposure-response relationship was observed, both for number of tobacco smoked and tobacco-PY and lung cancer risk. This association persisted across ethnic subgroups. One surprising finding is the strength of association for duration of tobacco used and lung cancer risk across the ethnic subgroups. For the longest duration of exposure, the strongest effect was observed among Brahmins, although their prevalence of consumption for the two highest risk products (choor/kankat and bidi) was lower than the other groups. This is consistent with the product specific risk (Table 3 ) as well as the risk associated with number of tobacco products smoked.

There are several strengths of this study. This is the first study to provide local tobacco specific risk estimates on lung cancer risk among a very diverse and underserved population in Nepal. The relatively large sample size allowed us to look at product specific risk. There are some limitations associated with our study as well. Mainly, complete independence was not achieved within the product specific tobacco categories. Our aim was to identify the product specific lung cancer risk. Secondly, the information regarding the tobacco types were assessed using a questionnaire, so potential recall bias cannot be ruled out. Even though it may be difficult to directly compare all types of tobacco smoking, we can reasonably conclude that smoking traditional tobacco products increases the risk of lung cancer more dramatically when compared with the non smoking population.

The implications of such results reinforce the dangerous health concerns surrounding smoking in low income countries. More precisely, those who smoke traditional or local types of tobacco products are at a higher risk for lung cancer when compared to other types of tobacco smoking and non smoking groups. The explanation of these differences may lie in the industrial processing of 
commercial tobacco compared to locally grown tobacco or that people may smoke traditional tobacco products more frequently due to misplaced perceptions of safety. Filtering of commercial cigarettes may play a role as well, but does not fully explain the commercial unfiltered cigarettes. While all tobacco products are harmful, our results show that the relative potency of the tobacco products is different. While risk perception is relatively high surrounding the role of tobacco and lung cancer, risk perception about other health effects, namely heart disease and other cancers, related to tobacco use is comparatively low which allows room for improved health messaging surrounding tobacco use (B. Gupta and Johnson, 2014a; 2014b; Peltzer and Pengpid, 2014). This comprehensive evaluation of various tobacco products and smoking habits within ethnic groups in Nepal is the first of its kind and further research is needed to investigate the cultural and social norms driving differential tobacco use.

In summary, some variation was observed between types of tobacco used across ethnic groups. Similarly, a marked variability was observed in the potency of local tobacco products, particularly choor/kankat. Our findings suggest these cheaper products that smokers buy in bulk and roll themselves are more harmful. This poses a particular challenge since the extensive warning signs that have been used in the packaging materials to warn against the harm of tobacco products are not applicable for such loose products. A separate intervention strategy is warranted to warn users of such cheap local products, who are more likely to be of low SES even by the LMIC standards.

\section{Acknowledgements}

All authors contributed significantly to the conceptualization, execution, and/or reporting of this research project. Bhola Siwakoti, Binary Kumar Thakur, and Chin Bahadur Pun recruited study participants and collected original data. Greg Raspanti and Amir Sapkota analyzed the data, conceived the research questions, and drafted the manuscript. Charles Milrod conducted literature review and contributed to manuscript drafts. Yuan-Chin Amy, Mia Hashibe, Subodh Adhikari, and Mei Wei contributed to data analysis and final manuscript preparation.

\section{References}

Bhagabaty S, Kataki A, Kalita M, et al (2015). Community based intervention for tobacco cessation: a pilot study experience, north East India. Asian Pac J Cancer Prev, 16, 811-4.

Binu V, Chandrashekhar T, Subba S, et al (2007). Cancer pattern in Western Nepal: a hospital based retrospective study. Asian Pac J Cancer Prev, 8, 183-6.

Chawla R, Sathian B, Mehra A, et al (2010). Awareness and assessment of risk factors for lung cancer in residents of pokhara valley, Nepal. Asian Pac J Cancer Prev, 11, 1789-93.

D'Souza N, Murthy N, Aras R (2013). Projection of cancer incident cases for India -till 2026. Asian Pac J Cancer Prev, 14, 4379-86.

Dikshit R, Kanhere S (2000). Tobacco habits and risk of lung, oropharyngeal and oral cavity cancer: a population-based case-control study in Bhopal, India. Int J Epidemiol, 29, 609-14.

Ganesh B, Sushama S, Monika S, et al (2011). A case-control study of risk factors for lung cancer in Mumbai, India. Asian Pac J Cancer Prev, 12, 357-62.

Ghosh A, Ghosh T (2009). Modification of Kuppuswamy's socioeconomic status scale in context to Nepal. Indian Pediatrics, 46, 1104-5.

Gupta B, Johnson N (2014). Emerging and established global life-style risk factors for cancer of the upper aero-digestive tract. Asian Pac J Cancer Prev, 15, 5983-91.

Gupta B and Kumar N (2014). A cross-country comparison of knowledge, attitudes and practices about tobacco use: findings from the global adult tobacco survey. Asian Pac J Cancer Prev, 15, 5035-42.

Gupta D, Boffetta P, Gaborieau V, et al (2001). Risk factors of lung cancer in chandigarh, India. Indian J Med Res, 113, 142-50.

Hashibe M, Siwakoti B, Wei M, et al (2011). Socioeconomic status and lung cancer risk in Nepal. Asian Pac J Cancer Prev, 12, 1083-8.

IARC (2012). http://globocan.iarc.fr/Pages/fact_sheets_cancer. aspx

ICF International (2012). Nepal demographic and health survey 2011. http://dhsprogram.com/pubs/pdf/FR257/ FR257\%5B13April2012\%5D.pdf

IOM (2007). Cancer control opportunities in low- and middleincome countries.

Jayalekshmy P, Akiba S, Nair M, et al (2008). Bidi smoking and lung cancer incidence among males in karunagappally cohort in Kerala, India. Int J Cancer, 123, 1390-7.

Jussawalla D and Jain D (1979). Lung cancer in greater bombay: correlations with religion and smoking habits. Br J Cancer, 40, 437-48.

Noronha V, Dikshit R, Raut N, et al (2012). Epidemiology of lung cancer in India: focus on the differences between nonsmokers and smokers: a single-centre experience. Indian $J$ Cancer, 49, 74-81.

Notani P and Sanghvi L (1974). A retrospective study of lung cancer in Bombay. Br J Cancer, 29, 477-82.

Notani P, Rao D, Sirsat M, et al (1977). A study of lung cancer in relation to bidi smoking in different religious communities in Bombay. Indian J Cancer, 14, 115-21.

Pednekar M, Gupta P, Yeole B, et al (2011). Association of tobacco habits, including bidi smoking, with overall and site-specific cancer incidence: results from the mumbai cohort study. Cancer Causes Control, 22, 859-68.

Peltzer K and Pengpid S (2014). Tobacco use, beliefs and risk awareness in university students from 24 low, middle and emerging economy countries. Asian Pac J Cancer Prev, 15, 10033-8.

Pradhananga K, Baral M, Shrestha B (2009). Multi-institution hospital-based cancer incidence data for Nepal: an initial report. Asian Pac J Cancer Prev, 10, 259-62.

Prasad R, Ahuja RC, Singhal S, et al (2010). A case-control study of bidi smoking and bronchogenic carcinoma. Ann Thorac Med, 5, 238-41.

Prasad R, Singhal S, Garg R (2009). Bidi smoking and lung cancer. Biosci Trends, 3, 41-3.

Sapkota A, Gajalakshmi V, Jetly D, et al (2008). Indoor air pollution from solid fuels and risk of hypopharyngeal/ laryngeal and lung cancers: a multicentric case-control study from India. Int J Epidemiol, 37, 321-8.

Thapa B, Sayami P (2014). Low lung cancer resection rates in a tertiary level thoracic center in Nepal--where lies our problem? Asian Pac J Cancer Prev, 15, 175-8.

WHO (2012). http://www.who.int/mediacentre/factsheets/fs297/ en/

World Bank (2012). http://data.worldbank.org/country/nepal 